\title{
Driving pressure and postoperative pulmonary complications in adult cardiac surgery
}

\author{
Bignami E. ${ }^{1}$, Pelosi P. ${ }^{2}$, Saglietti F. ${ }^{1}$, Guarnieri M. ${ }^{1}$, de Simone G. ${ }^{1}$, Zangrillo A. ${ }^{1}$ \\ ${ }^{1}$ San Raffaele Scientific Institute, University Vita Salute San Raffaele, Anesthesia and Intensive Care Unit, Milan, Italy, ${ }^{2}$ IRCCS AOU \\ San Martino IST, University of Genova, Department of Surgical Sciences and Integrated Diagnostics, Genova, Italy
}

Background and Goal of Study: Driving Pressure (DP) is the difference between the plateau pressure (Pplateau) and the Positive End-Expiratory Pressure (PEEP), and estimates the lung strain. In general surgery DP $>13 \mathrm{cmH}_{2} \mathrm{O}$ has been associated with an increased incidence of Postoperative Pulmonary Complications (PPCs) ${ }^{1}$. The aim of this study is to evaluate the predictive power of DP for clinical outcome in adult cardiac surgery.

Materials and Methods: This is a prospective observational study. After the Ethics Committee's approval, 200 patients were continuously enrolled from December 2015 to January 2017. We collected data provided by the anaesthesia machine: tidal volume, PEEP, $\mathrm{FiO}_{2}$, peak and Pplateau, lung compliance and DP. DP was measured after anaesthesia induction and at the end of surgery. Chi-square test was used for dichotomous variables, ztest/t-test or the Mann-Whitney U-test for continuous variables, as appropriate. Statistical significance if $p<0.05$.

Results and Discussion: The median DP after induction and at end of surgery were 12 (10-15) $\mathrm{cmH} 2 \mathrm{O}$ and $13 \mathrm{cmH}_{2} \mathrm{O}$ (10-16) $\mathrm{cmH} 2 \mathrm{O}$, respectively. $A$ total of 87 patients $(43.5 \%)$ had DP $>13$ at anaesthesia induction, $104(52 \%)$ at the end of surgery.

DP $>13 \mathrm{cmH}_{2} \mathrm{O}$ compared to DP $\leq 13 \mathrm{cmH}_{2} \mathrm{O}$ at anaesthesia induction yielded lower $\mathrm{PaO}_{2} / \mathrm{FiO}_{2}$ ratio at ICU discharge $(271.2 \pm 118.8$ vs $322.02 \pm 109.4 \mathrm{mmHg}$, respectively; $p=0.002$ ), higher need of Non Invasive Mechanical Ventilation (NIMV) $(44.8 \%$ vs $22.1 \%$, respectively; $\left.x^{2} 11.6 ; p=0.001\right)$ and an higher incidence of respiratory failure $(67.8 \%$ vs $\left.50.4 \% ; x^{2} 6.09 ; p=0.02\right)$. DP after anaesthesia induction showed also a weak correlation with both ICU stay ( $\rho$ 0.158; $p=0.026)$ and hospital stay ( $\rho$ 0.178; $p=0.012$ ).

DP $>13$ at the end of surgery yielded lower $\mathrm{PaO}_{2} / \mathrm{FiO}_{2}$ ratio at ICU discharge $(282.78 \pm 110.1$ vs $318.5 \pm 122.5 \mathrm{mmHg}$, respectively; $\mathrm{p}=0.032$ ) and higher need of $\operatorname{NIMV}(41.3 \%$ vs $21.9 \% ; p=0.003)$.

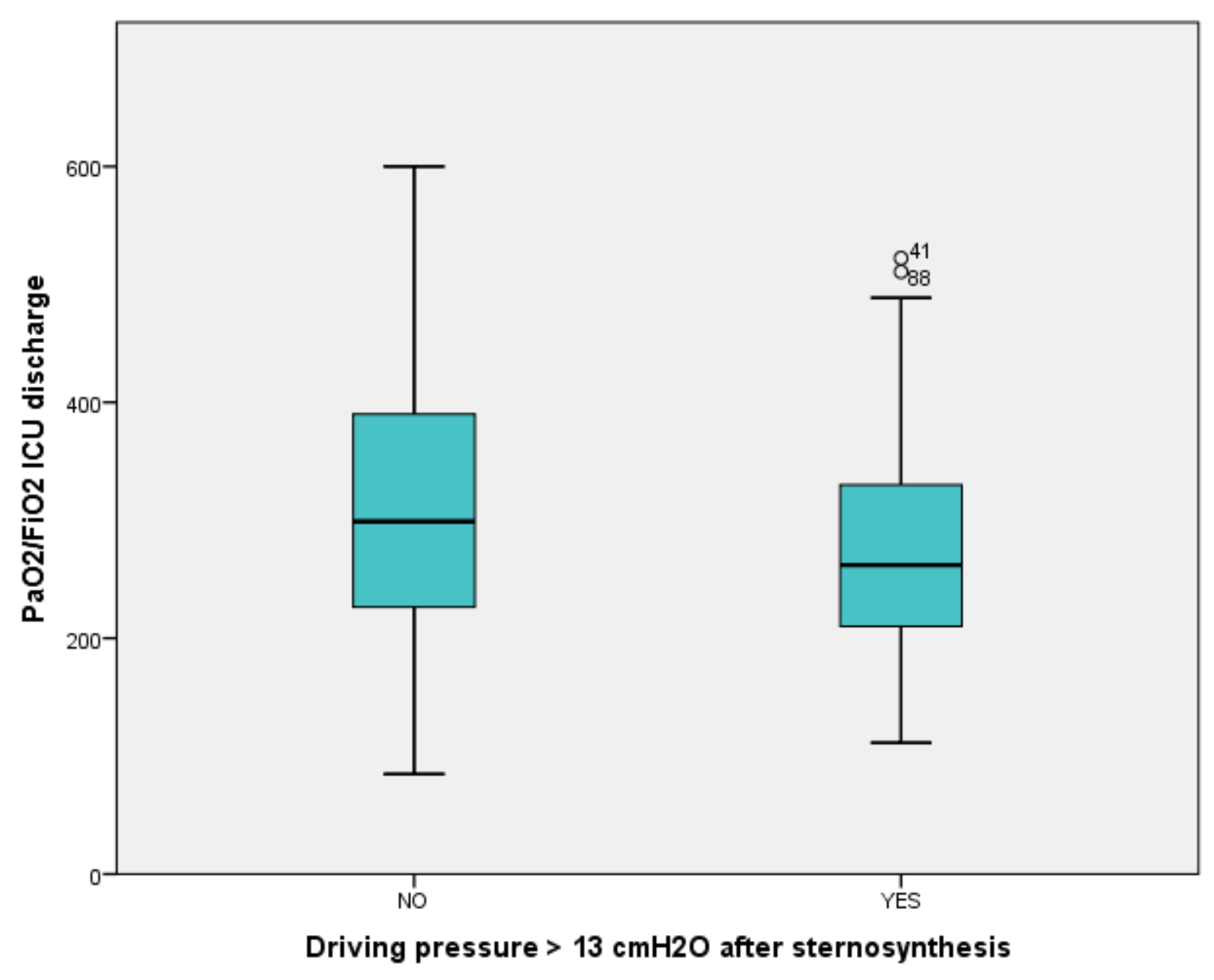

Conclusion(s): Monitoring DP during anaesthesia in cardiac surgery could help to identify those patients at increased risk of PPCs and optimise PEEP setting within the protective ventilation strategies. 